\title{
Population Biology of Pseudoperonospora humuli in Oregon and Washington
}

\author{
Hee Youn Chee, Mark E. Nelson, Gary G. Grove, Kenneth C. Eastwell, Stephen T. Kenny, and Robert E. \\ Klein, Irrigated Agriculture Research and Extension Center, Washington State University, 24106 N. Bunn Rd., \\ Prosser 99350
}

\begin{abstract}
Chee, H. Y., Nelson, M. E., Grove, G. G., Eastwell, K. C., Kenny, S. T., and Klein, R. E. 2006. Population biology of Pseudoperonospora humuli in Oregon and Washington. Plant Dis. 90:1283-1286.

Pseudoperonospora humuli populations from Oregon and Washington were analyzed for genetic variation using random amplified polymorphic DNA (RAPD) and DNA amplification fingerprinting (DAF) markers. The genetic structure of the Oregon and Washington populations differed considerably. There was little genetic diversity in Washington, with only five RAPD and six DAF groups detected among 40 isolates tested. One genotype was predominant in Washington. In contrast, 18 RAPD and 34 DAF groups were found among the 40 isolates tested from Oregon. No unique band profile associated with host cultivar was observed. It is suggested that the distinct difference in population structure between the two geographic regions might be due to climatic differences resulting in a higher frequency of sexual reproduction of $P$. humuli in Oregon than in Washington.
\end{abstract}

Additional keywords: downy mildew, hop, Humulus lupulus

Cultivated hop (Humulus lupulus L.) is an herbaceous and dioecious perennial plant. Each spring, shoots emerge from the rootstock (crown) and, when grown under cultivation, are trained up strings attached to a trellis system 5 to $6 \mathrm{~m}$ high. Lateral branching ensues when the vines have grown about halfway up the trellis. By late June or early July, apical growth ceases and flowering occurs on the lateral branches. Only the female plants produce cones used in beer and ale production to provide bitterness and hop aroma/flavor. The commercial value of hop cones lies in the lupulin glands which contain resins and essential oils including alpha and beta acids. Washington, Oregon, and Idaho account for approximately $23 \%$ of the total world's hop acreage and $36 \%$ of the total worldwide alpha acid production (6).

Downy mildew, caused by Pseudoperonospora humuli (Miyabe \& Takah.), is a

Corresponding author: M. E. Nelson

E-mail: mark_nelson@wsu.edu

Current address of H. Y. Chee: Biological Sciences, Konyang medical school. Nonsan-city, Chungnam, Korea. E-mail: hychee@konyang.ac.kr

Current address of R. E. Klein: California Pistachio Commission, Fresno, CA

E-mail: bobk@pistachios.org

Washington State University Plant Pathology New Series Manuscript No. 0407.

Accepted for publication 27 February 2006.

DOI: 10.1094/PD-90-1283

(C) 2006 The American Phytopathological Society serious disease of hop in the Pacific Northwest. It is more severe in areas of high rainfall such as the Willamette Valley of Oregon than in arid climates such as the Yakima Valley of Washington (16). Perennation of $P$. humuli occurs primarily in the hop crown, from which systemically infected shoots (basal spikes) emerge in the spring and early summer (4). Zoosporangia from these basal spikes serve as the primary inocula, and the pathogen spreads to healthy leaves and shoots under appropriate environmental conditions. Free water and mild temperatures favor sporulation and distribution of zoosporangia, followed by release of zoospores and secondary infection $(4,13)$. Oospores are formed in infected shoots and especially infected cones, but their role in the disease cycle has not been clearly established $(4,13)$. Because they are abundant and have occasionally been reported to germinate in the laboratory, it was assumed that oospores are partly responsible for the seasonal production of primary spikes associated with perennation $(1,7)$. However, repeated attempts to induce consistent germination of oospores in the laboratory or under field conditions have failed, and their role in the disease cycle is considered circumstantial (11).

Genetic markers generated by random amplified polymorphic DNA (RAPD) (17) have proven useful for studying genetics and phylogenetic relationships in a wide variety of fungi. A variation of the randomprimer-polymerase chain reaction (PCR) technique called DNA amplified fingerprinting (DAF) has been successfully employed in the identification of closely related organisms including viruses, bacteria, fungi, and plants (2). The objective of this research was to develop genetic markers suitable for characterizing the genetic structure of $P$. humuli populations, and utilize those techniques to compare diversity of the Oregon and Washington populations of this pathogen.

\section{MATERIALS AND METHODS}

Fungal isolates. Eighty hop basal spikes were collected from commercial fields and experimental plots in eight Oregon and six Washington hop yards. The 40 spikes from Oregon were collected from cultivars Nugget (20 isolates), Willamette (18 isolates), and Bullion (2 isolates). The 40 spikes from Washington were collected from cultivars Galena (13 isolates), Nugget (3 isolates), Cluster (18 isolates), and Chelan (6 isolates). The average distance between nearest neighboring sampled hop yards was $4.5 \mathrm{~km}$ (range 2.0 to $8.6 \mathrm{~km}$ ) in Oregon and $9.0 \mathrm{~km}$ (range 5.8 to $13.4 \mathrm{~km}$ ) in Washington. The greatest distance between sampled hop yards was $27 \mathrm{~km}$ in Oregon and $58 \mathrm{~km}$ in Washington.

Spikes were returned to the laboratory and sporulation of $P$. humuli induced by enclosing each individual spike in a plastic bag and incubating at $18^{\circ} \mathrm{C}$ for 12 to $18 \mathrm{~h}$ in darkness. Leaves exhibiting sporulation were harvested from each spike. Leaves that appeared contaminated with secondary microorganisms or otherwise degraded were not included in samples. Zoosporangia were harvested by vigorously shaking the infected leaves in distilled $\mathrm{H}_{2} \mathrm{O}\left(\mathrm{dH}_{2} \mathrm{O}\right)$ for $30 \mathrm{~s}$. Suspensions of zoosporangia were strained through several layers of cheesecloth, centrifuged at $1,200 \times g$ for 5 min, and the supernatant discarded. Pellets containing zoosporangia were resuspended in $\mathrm{dH}_{2} \mathrm{O}$ and centrifuged at $1,200 \times g$ for 5 min. The pellet was resuspended in $\mathrm{dH}_{2} \mathrm{O}$ and stored in a cryovial at $-70^{\circ} \mathrm{C}$ for future use.

DNA extraction. DNA was extracted directly from zoosporangia using an extraction procedure modified from the cetyltrimethylammonium bromide (CTAB) procedure of Murray and Thompson (8). Suspensions of zoosporangia were centrifuged at $1,200 \times g$ for $5 \mathrm{~min}$, resuspended in $0.5 \mathrm{ml}$ extraction buffer $(50 \mathrm{mM}$ Tris$\mathrm{HCl}, \mathrm{pH} 8.0,150 \mathrm{mM} \mathrm{NaCl}$, and $100 \mathrm{mM}$ EDTA), vortexed for 2 min with 450- to $600-\mu \mathrm{m}$-diameter glass beads, and transferred to a $1.5-\mathrm{ml}$ microcentrifuge tube After addition of $25 \mu \mathrm{l} 20 \%$ sodium dodecyl sulfate (SDS), the mixture was gently 
shaken for $60 \mathrm{~min}$ at room temperature followed by serial addition of $75 \mu$ of $5 \mathrm{M}$ $\mathrm{NaCl}$ and $65 \mu \mathrm{l}$ of $10 \% \mathrm{CTAB}$ in $0.7 \mathrm{M}$ $\mathrm{NaCl}$ followed by incubation at $65^{\circ} \mathrm{C}$ for $15 \mathrm{~min}$. The mixture was divided into two 1.5-ml microcentrifuge tubes, mixed 1:1 with chloroform/isoamyl alcohol (24:1), followed by centrifugation at $11,000 \times g$ at room temperature for $10 \mathrm{~min}$. The aqueous phase was transferred to a $1.5-\mathrm{ml}$ microcentrifuge tube, and nucleic acids were precipitated by addition of 0.6 volumes of cold isopropanol and incubation at $-20^{\circ} \mathrm{C}$ for $30 \mathrm{~min}$. Nucleic acids were pelleted by centrifugation at $11,000 \times g$ at room temperature for $5 \mathrm{~min}$. The pellet was rinsed twice with cold $70 \%$ ethanol (EtOH), dried in a transfer hood for $2 \mathrm{~h}$, and resuspended in $100 \mu \mathrm{l}$ of TE $(10 \mathrm{mM}$ Tris- $\mathrm{HCl}$ and 1 mM EDTA, pH 8.0). Contaminating RNA was completely digested by addition of 1 $\mu \mathrm{l}$ of ribonuclease A $(10 \mathrm{mg} / \mathrm{ml}$; Sigma Chemical Co., St. Louis, MO) and incubation at $4^{\circ} \mathrm{C}$ overnight. The DNA was reprecipitated by the addition of 0.1 volume

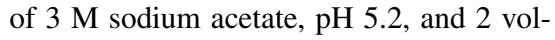
umes of $95 \% \mathrm{EtOH}$. After $20 \mathrm{~min}$ at $-20^{\circ} \mathrm{C}$, the nucleic acid was collected by centrifugation at $11,000 \times g$ for $5 \mathrm{~min}$, dried in a transfer chamber for $2 \mathrm{~h}$, dissolved in $100 \mu \mathrm{l}$ of $\mathrm{TE}$, and quantified using the minigel method described by Sambrook et al. (12). The purity of the DNA sample was further checked by spectrophotometric absorbance $\left(\mathrm{OD}_{260} / \mathrm{OD}_{280}\right)$.

RAPD analysis. A total of 120 decamer primers, including those listed in Table 1, were screened with $10 \mathrm{P}$. humuli isolates (five from Washington and five from Oregon) to select primers that exhibited good PCR amplification and consistent banding patterns following electrophoresis. RAPD amplification reactions (17) were performed in a $0.6-\mathrm{ml}$ microcentrifuge tube containing a final volume of $12.5 \mu \mathrm{l}$ of reaction mixture. The reaction mixture

Table 1. Number of scored and polymorphic random amplified polymorphic DNA (RAPD) bands produced by Pseudoperonospora humuli, using selected primers

\begin{tabular}{lccc}
\hline $\begin{array}{l}\text { Random } \\
\text { primer }\end{array}$ & $\begin{array}{c}\text { Primer sequence } \\
\left(\mathbf{5}^{\prime} \mathbf{3}^{\prime}\right)\end{array}$ & $\begin{array}{c}\text { Total } \\
\text { bands }\end{array}$ & $\begin{array}{c}\text { Poly- } \\
\text { morphic } \\
\text { bands }\end{array}$ \\
\hline OPA01 & CAGGCCCTTC & 7 & 0 \\
OPA03 & ACTCAGCCAC & 6 & 0 \\
OPA08 & GTGACGTAGG & 10 & 4 \\
OPA19 & CAAACGTCGG & 5 & 0 \\
OPB04 & GGACTGGAGT & 5 & 1 \\
OPB12 & CCTTGACGCA & 7 & 3 \\
OPB18 & CCACAGCAGT & 4 & 0 \\
OPC01 & TTCGAGCCAG & 6 & 2 \\
OPC05 & GATGACCGCC & 5 & 2 \\
OPC20 & ACTTCGCCAC & 6 & 0 \\
OPD05 & TGAGCGGACA & 5 & 0 \\
OPD07 & TTGGCACGGG & 5 & 1 \\
OPE18 & GGACTGCAGA & 5 & 0 \\
OPF09 & CCAAGCTTCC & 5 & 0 \\
OPF10 & GGAAGCTTGG & 4 & 0 \\
Total & & 85 & 13 \\
\hline
\end{tabular}

consisted of: $50 \mathrm{mM} \mathrm{KCl}, 10 \mathrm{mM}$ Tris$\mathrm{HCl}, \mathrm{pH}$ 9.0, 0.1\% Triton X-100, $200 \mu \mathrm{M}$ each dNTP, $0.2 \mu \mathrm{M}$ random primer (Operon Technology, Alameda, CA), 20 ng of genomic DNA, and 1 unit Taq polymerase (Promega, Madison, WI) overlaid with 50 $\mu \mathrm{l}$ of mineral oil (Sigma). The tubes were kept on ice during all manipulations. To confirm that observed bands were amplified DNA and not primer artifacts, genomic DNA was omitted for each primer as a control. Amplifications were conducted in a DNA thermocycler (Appligene Crocodile II, Synertron, Rohnert Park, CA) programmed for $5 \mathrm{~min}$ at $94^{\circ} \mathrm{C}$ followed by 45 cycles of $45 \mathrm{~s}$ at $94^{\circ} \mathrm{C}, 1 \mathrm{~min}$ at $36^{\circ} \mathrm{C}$, and $2 \mathrm{~min}$ at $72^{\circ} \mathrm{C}$, with final extension for 7 min at $72^{\circ} \mathrm{C}$.

Amplification products were separated by electrophoresis on $1.5 \%$ agarose (Amersham, Madison, WI) gels for $90 \mathrm{~min}$ at $100 \mathrm{~V}$ in TBE buffer (0.09 M Tris, 0.09 M boric acid, and 0.002 M EDTA, pH 8.0). DNA bands were stained with ethidium bromide and photographed. Reproducibility of RAPD patterns was tested with two independent replicates of each PCR assay. Only clear and distinct bands were included in the analysis.

DAF. Seven arbitrary primers, seven or eight nucleotides in length, were screened with 10 isolates using a modification of the Caetano-Anolles (2) DAF technique. The $12-\mu \mathrm{l}$ reaction mixture contained $50 \mathrm{mM}$ $\mathrm{KCl}, 10 \mathrm{mM}$ Tris- $\mathrm{HCl}, \mathrm{pH} 9.0,0.1 \%$ Triton $\mathrm{X}-100,200 \mu \mathrm{M}$ dNTP, $6 \mathrm{mM} \mathrm{MgCl}_{2}$, 10 ng template DNA, $3 \mu \mathrm{M}$ primer, and 2 units Taq polymerase (Promega). Cycling parameters included an initial denaturation at $96^{\circ} \mathrm{C}$ for $4 \mathrm{~min}$, followed by 30 cycles of $1 \mathrm{~s}$ at $96^{\circ} \mathrm{C}, 1 \mathrm{~s}$ at $36^{\circ} \mathrm{C}$, and $5 \mathrm{~s}$ at $72^{\circ} \mathrm{C}$. Amplified products were separated on $8 \%$ polyacrylamide gels $(8.3 \times 10.2 \mathrm{~cm})$ at 90 $\mathrm{V}$ in TBE buffer. DNA bands were silverstained, examined on a light box, and photographed.

Data analysis. Genetic variation among isolates was assessed by comparing the PCR amplified band profiles of all primerisolate combinations. Reproducible amplified DNA fragments were scored for all isolates based on presence or absence. Very intense bands were referred to as major bands and less intense bands were referred to as minor bands. Intensity of bands was determined by visual observa-
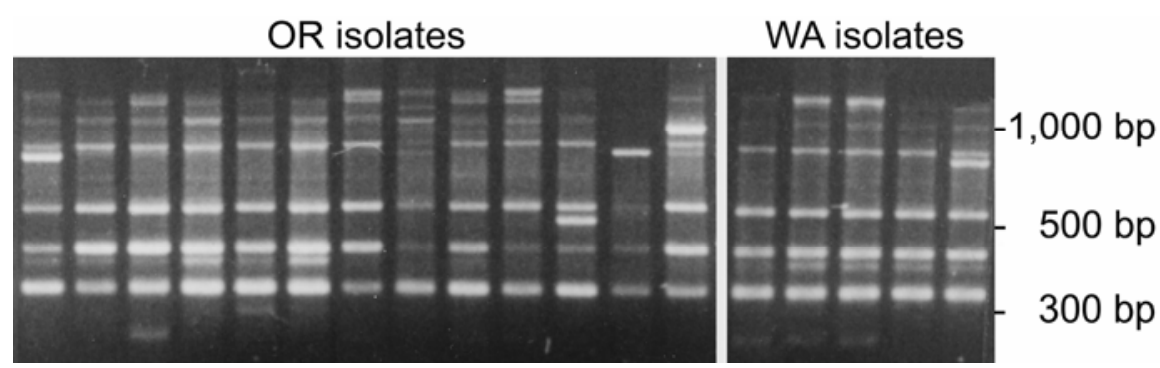

Fig. 1. Agarose gel electrophoresis of random amplified polymorphic DNA (RAPD) products from DNA of Pseudoperonospora humuli isolates using primer OPB 12 (CCTTGACGCA). tion. Variability was assessed within and among geographic regions, as well as host cultivar regardless of the geographic origin. A DNA fingerprinting similarity index (9) was used to quantify the genetic variation among $P$. humuli isolates collected from the two geographic regions.

Unique bands or band profiles associated with host cultivar or geographic region were evaluated by comparing all primer/isolate PCR products. Profiles for each primer were compared on the basis of the presence or absence of the RAPD and DAF products of identical length, and these data were used to calculate similarity coefficients. The SHAN program of NTSYS-PC Software (Numerical Taxonomy System, Version 1.8, Exeter Publishing Ltd., Setauket, NY) was utilized to compute the matrix of similarity coefficients among isolates (SIMQUAL function) (10). The range and average of similarity coefficients among isolates within a geographic region were used to assess genetic diversity. Differences in genetic polymorphisms between the two geographic regions were determined by measuring genotype diversity based on the Shannon-Weaver Index $(\mathrm{H})$ :

$$
H=-\Sigma P_{i} \ln P_{i}
$$

where $P_{i}$ is the frequency of a given band profile based on RAPD and DAF data (5).

\section{RESULTS}

RAPD analysis. Discrete DNA fragments were amplified from genomic DNA using 10-base random primers (Fig. 1). Of the 120 primers screened, 73 primers $(61 \%)$ produced discrete DNA fragments. Fifteen primers (Table 1) that showed consistent amplification and band profiles were selected for future studies. The selected oligonucleotide primers generated a total of 85 DNA amplification products in the 80 isolates studied. The number of bands generated by each primer varied from 4 to 10 . The amplified fragments ranged from 400 to $1,500 \mathrm{bp}$. Among the 85 RAPD markers, 72 monomorphic and 13 polymorphic bands were observed (Table 1).

Primers differed in their ability to generate polymorphisms. Nine random primers gave nearly identical banding patterns for all isolates, and six primers generated 
polymorphism between isolates. Major bands with strong intensities were highly reproducible, but some bands had variable intensities on repeat runs. The cause of this variation was not determined. All primers produced bands common to all isolates. In addition, isolates from Oregon usually produced more bands than isolates from Washington. For example, OPC05 primer produced two or three additional major bands with Oregon isolates. Similarity between isolates and the number of unique genotypes was primer dependent. Variation in the specific pattern of one isolate compared with others was inconsistent in that it was observed with one primer but not with another. The relationships among isolates were more clearly represented by a similarity matrix. In construction of the matrix, it was assumed that corresponding bands arose by amplification of the same genetic locus. All isolate combinations within a population were assigned similarity values based on the assumption that corresponding bands represented amplification of the same genetic locus. The similarity value within populations appeared to be different between the two geographic regions. Most isolates in Washington generated nearly identical banding patterns among isolates with similarity coefficients ranging from 97.6 to $100 \%$ with an average of $99.7 \%$. In Oregon, the average similarity coefficient value among isolates was $95.6 \%$, ranging from 90.6 to $100 \%$.

Genotype diversity of Oregon isolates (2.857) based on the Shannon-Weaver Index was greater than that of Washington (0.348). While 18 genotypes (RAPD groups) were found in Oregon, only five were found in Washington. Thirty-six of 40 Washington isolates (90\%) showed identical RAPD profiles, while the remaining four showed unique banding patterns. The Oregon isolates were not skewed to one genotype but more evenly distributed (Fig. 2). The dominant Washington genotype was also detected in Oregon (six isolates).

DAF PCR. In preliminary tests, seven primers were used to amplify genomic DNA from 10 isolates. Clear and reproducible polymorphic bands were obtained with DAF03 and DAF04 primers. Those

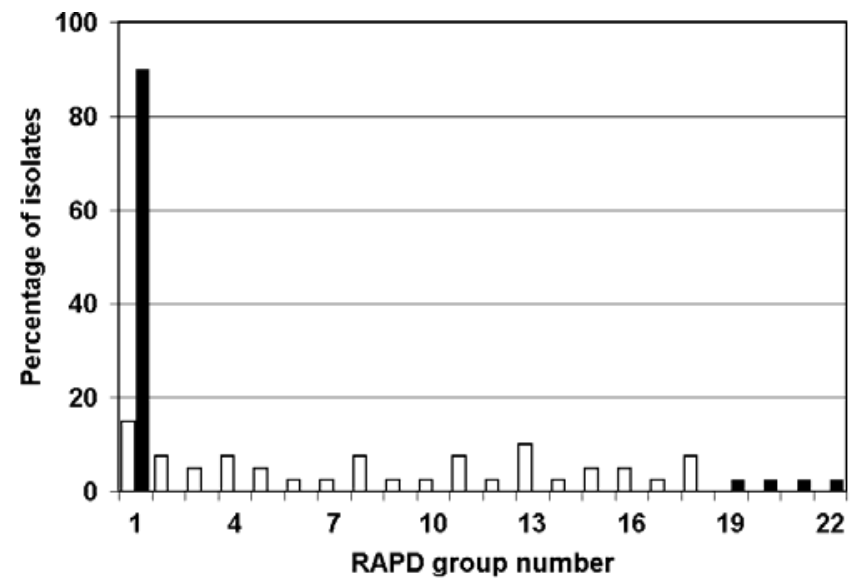

Fig. 2. Incidence of random amplified polymorphic DNA (RAPD) groups in Oregon ( $\square$ ) and Washington (ם). Values are percent population of each state. Group 1 was the only group detected in both states.

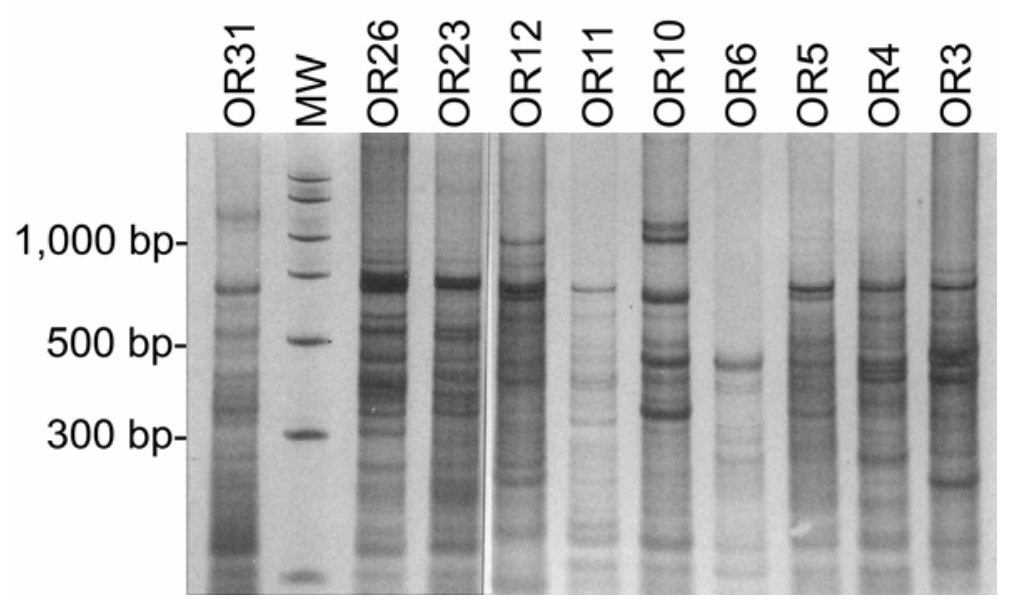

Fig. 3. DNA amplification fingerprinting (DAF) profiles of Pseudoperonospora humuli isolates from Oregon and Washington using the DAF03 primer (GTTACGCC).

two primers were used to amplify genomic DNA of all 80 isolates. Typically, 5 to 10 major bands and 10 to 15 minor bands were produced by each primer. A total of 32 bands were scored of which 22 were polymorphic (Table 2). Most amplified DNA fragments were between 300 and 1,500 bp in size (Fig. 3).

Similarity coefficients based on DAF analysis indicated a largely uniform population in Washington and a highly variable population in Oregon. Similarity coefficients of Washington isolates ranged from 87.5 to $100 \%$, with an average of $97.6 \%$. Similarity coefficients of isolates from Oregon averaged $79.2 \%$, ranging from 62.5 to $100 \%$. Genotype diversity based on the Shannon-Weaver Index was 3.455 and 0.898 in Oregon and Washington, respectively. While 34 genotypes were found in Oregon, only six were found in Washington (Fig. 4). Thirty-four of the 40 Washington isolates showed $100 \%$ similarity between isolates. No banding patterns were found in both geographical regions. Bands or band profiles unique to the host cultivar were not found.

\section{DISCUSSION}

In this study, DNA polymorphisms generated by RAPD and DAF techniques were examined in an attempt to characterize the population structure of $P$. humuli in Oregon and Washington. RAPD analysis detected greater differences in genetic variability among isolates from Oregon than among isolates from Washington. Isolates from Washington were nearly clonal, with $90 \%$ belonging to a single genotype, while 18 genotypes were found among the 40 Oregon isolates. The DAF technique detected a large number of polymorphisms among isolates and was more sensitive than RAPD analysis in estimating the degree of genetic variation among isolates of $P$. humuli on the basis of similarity coefficients and genotype diversity. The premise of genetic homogeneity in the Washington population in contrast to relatively high diversity in Oregon was strongly supported by average similarity coefficients of 97.6 and $79.2 \%$ based on DAF markers. While 34 different DAF patterns were observed among the 40 Oregon isolates, only six were found from Washington, including one dominant type that comprised $85 \%$ of the 40 Washington isolates. Moreover, the DAF- and RAPD-based analyses both

Table 2. Number of scored and polymorphic DNA amplification fingerprinting (DAF) bands produced by Pseudoperonospora humuli, using selected primers

\begin{tabular}{llcc}
\hline $\begin{array}{l}\text { Random } \\
\text { primer }\end{array}$ & $\begin{array}{l}\text { Primer } \\
\text { sequence }\left(\mathbf{5}^{\prime} \mathbf{- 3} \text { ') }\right.\end{array}$ & $\begin{array}{c}\text { Total } \\
\text { bands }\end{array}$ & $\begin{array}{c}\text { Poly- } \\
\text { morphic } \\
\text { bands }\end{array}$ \\
\hline DAF03 & GTTACGCC & 17 & 12 \\
DAF04 & GAAACGCC & 15 & 10 \\
Total & & 32 & 22 \\
\hline
\end{tabular}

Plant Disease / October 20061285 


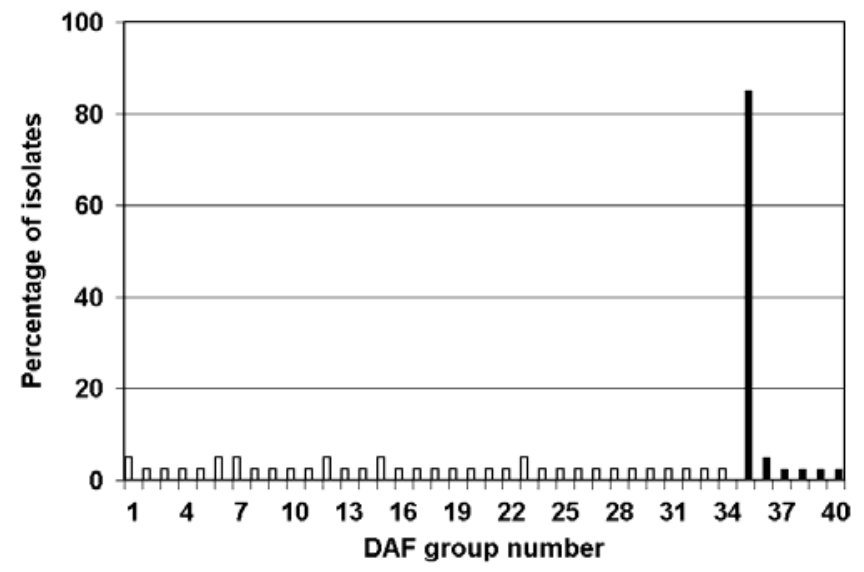

Fig. 4. Incidence of DNA amplification fingerprinting (DAF) groups found in Oregon ( $\square$ ) and Washington (ם). Values are percent population of each state. No banding patterns were found in both states.

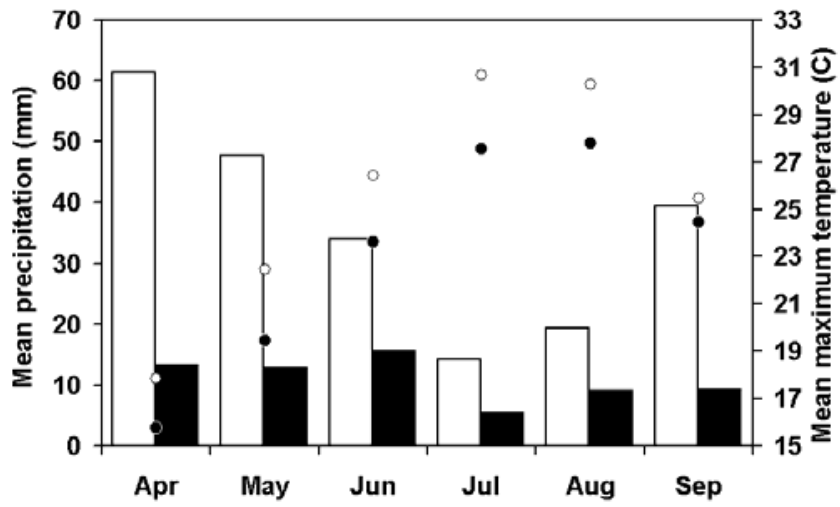

Fig. 5. Mean monthly precipitation and average maximum temperature in the hop-growing regions of Oregon and Washington. The mean daily maximum temperatures for Salem, OR $(\bullet)$ and Yakima, WA (O) are based on 30-year and 40-year averages, as is the average total monthly precipitation (Salem, OR: $\square$; Yakima, WA: $\mathbf{0}$ ). Source: National Climate Data Center (online).

revealed similar degrees of genotypic diversity when the two geographic regions are compared, namely, that there are few isolates displaying variation from Washington relative to the diversity observed in those from Oregon.

The distinct differences in $P$. humuli population structures between the two geographic regions suggest that sexual reproduction might be more important in the Oregon production area than in the Washington production area. Although the role of sexual reproduction of $P$. humuli in the disease cycle is not well understood, it has long been known that oospores can be found in infected hop tissue in most hop growing areas of the world, including both Oregon and Washington $(1,13,14)$. Skotland (13), however, demonstrated that $P$. humuli overwinters as mycelium in infected hop rootstock and suggested that oospores in the soil are probably of little importance in the Yakima Valley of Washington. Oospores are rare in the Yakima Valley because the dry, hot summer weather inhibits secondary spread and aboveground infected tissue desiccates rapidly (15). Furthermore, Chee and Klein (3) demonstrated that oospore production could be induced in the laboratory with $P$. humuli isolates collected from both Oregon and Washington but that high temperatures inhibited oospore formation. Figure 5 illustrates the climatic differences between the western Oregon (relatively cool and wet) and central Washington (relatively warm and dry) hop growing areas during the growing season. These reports suggest that oospore development is affected by local environmental factors. Favorable environmental factors such as high rainfall and low temperature combined with high disease incidence might induce relatively active sexual reproduction in the Willamette Valley of Oregon. Conversely, hot and dry weather, and resulting low disease incidence, might impede sexual reproduction in the Yakima Valley of Washington. In the present study, some isolates were found with identical RAPD and DAF markers in Oregon, suggesting that sexual reproduction might be followed by several rounds of asexual reproduction. The nearly clonal population structure in Washington suggests limited or no sexual reproduction.

This study compares the number of $P$. humuli genotypes measured by RAPD and DAF analysis that occur in two geographi- cally defined areas with differing climates and disease incidence. This description provides the foundation for future research on the genetics, population structure, and epidemiology of this pathogen. While it is suggested that the greater number of genotypes detected in Oregon compared with Washington may be due to a greater incidence of sexual reproduction in Oregon, additional research is needed to better understand the role of sexual reproduction in these populations.

\section{ACKNOWLEDGMENTS}

Support for this research was provided by grants from Busch Agricultural Resources Inc., Hop Research Council, Miller Brewing Co., Oregon Hop Commission, and Washington Hop Commission.

\section{LITERATURE CITED}

1. Bressman, E. N., and Nichols, R. A. 1933. Germination of the oospores of Pseudoperonospora humuli. Phytopathology 23:485-486.

2. Caetano-Anolles, G. 1993. Amplifying DNA with arbitrary oligonucleotide primers. PCR Methods Applications 3:85-94.

3. Chee, H. Y., and Klein, R. E. 1998. Laboratory Production of Oospores in Pseudoperonospora humuli. Korean J. Plant Pathol. 14:618-621.

4. Coley-Smith, J. R. 1962. Overwintering of hop downy mildew Pseudoperonospora humuli (Miy. et Tak.) Wilson. Ann. Appl. Biol. 50:235-243

5. King, L. M., and Schaal, B. A. 1989. Ribosomal-DNA variation and distribution in Rudbeckia missouriensis. Evolution 43:1117-1119.

6. MacKinnon, D. 2004. USA Hops 2004 Statistical Report. Hops Growers of America, Yakima, WA.

7. Magie, R. O. 1942. The epidemiology and control of downy mildew on hops. NY State Agric. Exp. Stn. (Geneva) Tech. Bull. 267.

8. Murray, M. G., and Thompson, W. F. 1980. Rapid isolation of high molecular weight plant DNA. Nucleic Acids Res. 8:4321-4325.

9. Nei, M., and Li, W. 1979. Mathematical model for studying genetic variations in terms of restriction endonuclease. Proc. Natl. Acad. Sci. USA 76:5269-5273.

10. Rohlf, F. J. 1993. NTSYS-PC: Numerical Taxonomy System, Version 1.8. Exeter Publishing Ltd., Setauket, NY.

11. Royle, D. J., and Kremheller, H. TH. 1981 Downy mildew of the hop. Pages 395-419 in The Downy Mildews. D. M. Spencer, ed. Academic Press, New York.

12. Sambrook, J., Fritsch, E. F., and Maniatis, T. 1989. Molecular Cloning: A Laboratory Manual. 2nd ed. Cold Spring Harbor Laboratory Press, Plainview, NY.

13. Skotland, C. B. 1961. Infection of hop crowns and roots by Pseudoperonospora humuli and its relation to crown and root rot and overwintering of the pathogen. Phytopathology 51:241-244.

14. Skotland, C. B. 1964. Life cycle of the hop downy mildew fungus. Hop downy mildew $-\mathrm{A}$ symposium. Modern Brewery Age. May 1964.

15. Skotland, C. B., and Johnson, D. A. 1983 Control of downy mildew of hops. Plant Dis. 67:1183-1185.

16. Skotland, C. B., and Romanko, R. R. 1964. Life history of the downy mildew fungus. Wash. Agric. Exp. Stn. Circ. 433.

17. Williams, J. G., Kubelik, A. R., Livak, K. J., Rafalski, J. A., and Tingey, S. V. 1990. DNA polymorphisms amplified by arbitrary primers are useful as genetic markers. Nucleic Acids Res. 18:6531-6535. 